\title{
Optimization and emergence in marine ecosystem models
}

\author{
Mariani, Patrizio; Visser, Andre
}

Published in:

Progress in Oceanography

Link to article, DOI:

10.1016/j.pocean.2009.09.010

Publication date:

2010

Link back to DTU Orbit

Citation (APA):

Mariani, P., \& Visser, A. (2010). Optimization and emergence in marine ecosystem models. Progress in Oceanography, 84(1-2), 89-92. https://doi.org/10.1016/j.pocean.2009.09.010

\section{General rights}

Copyright and moral rights for the publications made accessible in the public portal are retained by the authors and/or other copyright owners and it is a condition of accessing publications that users recognise and abide by the legal requirements associated with these rights.

- Users may download and print one copy of any publication from the public portal for the purpose of private study or research.

- You may not further distribute the material or use it for any profit-making activity or commercial gain

- You may freely distribute the URL identifying the publication in the public portal

If you believe that this document breaches copyright please contact us providing details, and we will remove access to the work immediately and investigate your claim 
(c) 2009 Elsevier Ltd All rights reserved.

\title{
Optimization and emergence in marine ecosystem models
}

\author{
Patrizio Mariani ${ }^{\mathbf{a},{ }^{*}}$ and André W. Visser ${ }^{\mathbf{a}}$ \\ a Technical University of Denmark, National Institute for Aquatic Resources, Kavalergaarden 6, DK-2920 \\ Charlottenlund, Denmark \\ *: Corresponding author : Patrizio Mariani, email address : pat@aqua.dtu.dk
}

\begin{abstract}
:
Ingestion rates and mortality rates of zooplankton are dynamic parameters reflecting a behavioural trade-off between encounters with food and predators. An evolutionarily consistent behaviour is that which optimizes the trade-off in terms of the fitness conferred to an individual. We argue that interaction rates used in models, rather than being prescribed, should be dynamic emerging properties that reflect this optimization. A simple example illustrates how predator and prey abundance, and prey community structure, can instigate prey switching with cascading trophic effects.
\end{abstract}

Keywords : Optimization, Behaviour, Zooplankton, Trophic Interactions, Fitness 


\section{Introduction}

Over the past 30 years, the modelling of marine ecosystems has followed an approach dictated predominantly by a physico-chemical point of view; that the distribution and abundance of species can be described by continuum fields of compartmentalized functional groups, and their trophic interactions as fluxes of a stoichiometry relevant tracer between these compartments. The rationale of this representation is that it slips seamlessly into existing models of ocean circulation and biogeochemical cycling. As a consequence however, the modelled ecosystem, its structure, complexity, biodiversity and how these adapt to changing conditions are all fixed by the model architecture (cf Denman 2003). The use of a few functional groups rather than organisms with continuum traits prevents the representation of the community structure as an emerging property driven by competition, predation and environmental forcing (Norberg 2004).

Of particular concern is the lack of plasticity in the behavioural and life history traits, which hinders the ability of ecosystem models to track adaptations to changing ecological and environmental conditions. We consider this aspect a strong limitation of classical biogeochemical approaches in modelling the effects of expected climate change on marine ecosystems. Indeed, we can confidently hypothesize that a changing environment will induce changes in the community structure and functioning of the ecosystem rather than simple changes in biomass and flux of its components.

Considering that biological rates are variable, and not rigid parameters as in current models, we propose here a method based on optimal behaviour of planktonic individuals that can be used to derive, for example, adaptive ingestion and mortality rates of zooplankton species. This methodology might constitute a simple way to incorporate at least some aspects of behavioural plasticity into existing biogeochemical models.

\section{Optimal behaviour model for zooplankton}

Zooplankton faces three tasks: find food, reproduce, and avoid predation. They do so by encountering other organisms. For zooplankton, encounter rates (with food, mates and predators) are in many cases linked to how the organism moves through its environment, and this behaviour can be adapted to different conditions (e.g. low food conditions, high predation risks, etc.). The expected trade-off between beneficial and detrimental encounters can be analyzed as a function of the swimming behaviour and the environmental conditions. An evolutionary consistent behaviour is that which optimizes an individual's fitness in terms of the rate at which it acquires energy for reproduction and its survival in the face of predation risk. A parameter that at least in part captures the foraging-predation trade-off with respect to individual fitness is :

$$
g(b)=\frac{E(b)}{\mu(b)}
$$

(Gilliam \& Fraser 1987 ; Visser 2007) where $E$ is the rate of the energy intake and $\mu$ the organism's mortality rate, both function of the behaviour $(b)$ that can be adapted to different conditions i.e., by changes in the swimming speed. While this fitness estimator is not universally applicable (Aksnes \& Giske 1990 ; Railsback et al 1999), it can be shown to be appropriate for a mature individual 
competing with similar individuals for a common limiting resource in a stable environment (Clark 1994). Under these assumptions, the behaviour $b^{*}$ that maximizes $g(b)$ may be deemed optimal in terms of fitness.

\section{Results}

Many copepods exhibits different feeding modes: suspension or cruise feeding on small phytoplankton cells and ambush feeding on motile prey (Tiselius \& Jonsson 1990 ; Kiørboe et al 1996 ; Alcaraz et al 2007). We illustrate how this behaviour switching emerges from optimization in a highly-idealized example; a hypothetical copepod consumer (e.g. Acartia tonsa) sandwiched between a predator (e.g. larval fish) and a community of protist prey, some of which swim and some of which are immotile.

Our estimate of maximum fitness is an increasing function of both prey type composition and prey concentration (Figure 1). However, an increase in prey abundance does not always correspond to higher ingestion rate since behavioural switching effects can emerge when predation risk is considered at intermediate and high prey concentrations (Fig. 1).

For example at $C=10^{8}$ cell $/ \mathrm{m}^{3}$, when the fraction of motile prey falls below of $\sim 65 \%$, optimal behaviour is a swimming velocity in the range $2.2-1.5 \mathrm{~mm} / \mathrm{s}$. As the relative abundance of motile prey items increases, the fitness of the optimal strategy, $g\left(b^{*}\right)$, slowly increases until the optimal velocity switches to zero, i.e. copepods switch to an ambush feeding with a strong increases in $g\left(b^{*}\right)$ (Fig. 1). These results are function of the relative predator and prey abundances.

Therefore, changes in the predator and prey concentrations and/or in the prey composition can induce modification of the optimal swimming behaviour. This in turn produces changes in the realized vital rates of the copepods. Figure 2 shows how ingestion (Fig. 2a,b) and mortality (Fig. 2c,d) rates are modified by changes in the swimming speed of the copepod feeding on mixed composition of motile and static prey at two different concentrations.

Moving from a cruising into an ambush strategy at lower concentration produces a ca. 40\% reduction of the ingestion rates and a ca. $60 \%$ reduction of the mortality rate, with a strong increase in the fitness (Fig. 1b). Less marked but still important and similar effects are obtained at the higher prey concentration (dashed line in Fig. 2c,d and Fig 1b).

\section{Discussion}

The marine ecosystem is a complex adaptive system. It is complex in that it is composed of many inter-relationships (Levin 1999). What ever the means by which these inter-relationships are viewed, (from a functional group, population, or species perspective) they ultimately manifest at the individual level, where the rules of engagement are dictated only by the individuals' evolutionary self-interest. This is additional information that can be mobilized in ecosystem models; vital rates such as growth, grazing and mortality emerge as properties of the population rather than being imposed as model parameters. 
In a simple example, we illustrate how this works. The simulation does not pretend to describe an actual situation, there being any number of complicating elements in encounter processes. Nonetheless, it shows that optimal swimming speed in copepods is function of both predator and prey abundance, and prey community characteristics. Specifically, if we assume that in nature, where predator and prey abundances vary, and organisms adopt their optimal swimming speed, then the functional form of realized ingestion rates and mortality rates are dynamic, and will be other than that commonly assumed.

In this, we can only give a flavour of how adaptive traits and optimization can be utilized, and a full implementation in ecosystem models is still far-off. As a proof of concept, we can point to the work of Steele \& Clark (1998) who implemented optimization rules for trophic interactions in an NPZ model using a dynamic programming approach. We realize that there is any number of complication issues; for instance different behavioural rules apply at different life stages, the cues triggering behaviour are limited by the sensory abilities of the organisms involved, and seasonally controlled generation cycles. However, in so far as NPZ-type models are concerned, we can offer dynamically determined, rather than prescribed functional response curves, where the dynamic determination arises through adaptive behaviour as shaped by evolutionary processes. That is, if credible conjectures can be posed as to how organisms adapt their behaviour to meet the opportunities and challenges of changing conditions, and these conjectures can be mechanistically quantified, then optimal behaviour and subsequent vital rates can be modelled in a dynamic manner.

\section{Acknowledgements}

PM would like to thank IGBP programs IMBER and GLOBEC as well as the Network of Excellence EUR-OCEANS of the European Union's 6th Framework Program for funding the symposium on "Parameterization of Trophic Interactions in Ecosystem Modelling", Cadiz, March 2007, and the meeting conveners for the invitation to participate. This study was supported by Danish Research Agency grants 21-04-0391 and 21-03-0299. We would like to thank Thomas Kiørboe for discussion and advice. PM was supported by a EUR-OCEANS postdoctoral fellow grant.

\section{References}

Aksnes DL, Giske J (1990) Habitat profitability in pelagic environments. Mar.Ecol.Prog.Ser. 64:209215

Alcaraz M, Saiz E, Calbet A (2007) Centropages behaviour: Swimming and vertical migration. Prog Oceanog 72:121-136

Clark CW (1994) Antipredator behavior and the asset-protection principle. Behavioral Ecology 5:159161

Denman K (2003) Modelling planktonic ecosystems: parameterizing complexity. Prog Oceanog 57:429-452 
Gilliam JF, Fraser DF (1987) Habitat selection under predation hazard: test of a model with streamdwelling minnows. Ecology 68:1856-1862

Kiørboe T, Saiz E, Viitasalo M (1996) Prey switching behaviour in the planktonic copepod Acartia tonsa. Marine Ecology-Progress Series 143:65-75

Levin SA (1999) Fragile dominion: Complexity and the commons. Perseus Publishing, Cambridge, MA.

Norberg J (2004) Biodiversity and ecosystem functioning: A complex adaptive systems approach. Limnol.Oceanogr. 49:1269-1277

Railsback SF, Lamberson RH, Harvey BC, Duffy WE (1999) Movement rules for individual-based models of stream fish. Ecol.Model. 123:73-89

Steele JH, Clark CW (1998) Relationships between individual- and population-based plankton models. J.Plankton Res. 20:1403-1415

Tiselius P, Jonsson PR (1990) Foraging behaviour of six calanoid copepods: observations and hydrodynamic analysis. Mar.Ecol.Prog.Ser. 66:23-33

Visser AW (2007) Motility of zooplankton: fitness, foraging and predation. J.Plankton Res. 29:447-461 
Tables

Table 1 : Parameters and functions used in the model.

\begin{tabular}{|c|c|}
\hline$E=e I-m-q v^{2}$ & Energy intake \\
\hline$\mu=\mu_{0}+Z_{\text {Pred }}$ & Mortality \\
\hline$I=\frac{Z_{\text {Prey }}}{1+h Z_{\text {Prey }}}$ & Ingestion rate \\
\hline$Z_{\text {Prey }}=\pi R_{\text {Prey }}^{2} C\left(u^{2}+v^{2}\right)^{1 / 2}$ & Encounter rate to prey \\
\hline$Z_{\text {Pred }}=\left(\frac{2}{3} \pi R_{\text {Pred }}^{3} \alpha\right) P \frac{1}{\left(T_{C}+T_{P}\right)}+\pi R_{\text {Pred }}^{2} P v \frac{T_{P}}{\left(T_{C}+T_{P}\right)}$ & $\begin{array}{l}\text { Encounter rate to a pause-travel } \\
\text { predator }\end{array}$ \\
\hline $\mathrm{e}=10^{-6} \mathrm{Joule} /$ cell & $\begin{array}{l}\text { Per capita energy content of a prey cell } \\
\text { that can be assimilated }\end{array}$ \\
\hline $\mathrm{m}=10^{-9}$ Joule $/ \mathrm{s}$ & Basal metabolic cost of $A$. tonsa \\
\hline$\mu_{0}=10^{-7} 1 / \mathrm{s}$ & Background mortality rate \\
\hline $\mathrm{h}=4 \mathrm{~s}$ & Handling time \\
\hline$q=5 \cdot 10^{-7}$ Joule $/$ second $\mathrm{s}^{2} / \mathrm{m}^{2}$ & Swimming cost (see Visser 2007) \\
\hline$R_{\text {Prey }}=5 \cdot 10^{-4} \mathrm{~m}$ & Copepod reaction distance \\
\hline $\mathrm{u}=10^{-3} \mathrm{~m} / \mathrm{s}$ & Prey swimming velocity \\
\hline $\mathrm{R}_{\text {Pred }}=10 \cdot \mathrm{R}_{\text {Prey }} \mathrm{m}$ & Predator reaction distance \\
\hline $\mathrm{T}_{\mathrm{C}}=2.0 \mathrm{~s}, \mathrm{~T}_{\mathrm{P}}=1.0 \mathrm{~s}$ & Predator cruising and pause time \\
\hline$\alpha=0.4$ & $\begin{array}{l}\text { Scaling factor of the search volume } \\
\text { overlap for a pause travel predator }\end{array}$ \\
\hline
\end{tabular}




\section{Figures}

Figure 1 : Estimated maximum fitness $g\left(b^{*}\right)$ as function of prey concentration and prey type composition expressed as the fraction of motile organisms ( 0 only static prey; 100 only motile prey where $u=1 \mathrm{~mm} / \mathrm{s}$ ). A colour map showing the optimal swimming velocity in the range 0 (black) 10 (white) $\mathrm{mm} / \mathrm{s}$ has also been superimposed. Solid lines show $\mathrm{g}\left(\mathrm{b}^{*}\right)$ at two prey concentrations $\mathrm{C}=10^{8}$ prey $/ \mathrm{m}^{3}$ and $C=10^{9}$ prey $/ \mathrm{m}^{3}$. Predator concentration is $P=40$ predator $/ \mathrm{m}^{3}$. Also shown, the lines (dashed) of $0,50 \%$ and $100 \%$ of the fraction of motile prey. Note the switch to zero of the optimal velocity at $\sim 65 \%$ when $C=10^{8}$ prey $/ \mathrm{m}^{3}$ and at $40 \%$ when $\mathrm{C}=10^{9} \mathrm{prey} / \mathrm{m}^{3}$. Optimal velocity is also zero at low prey concentrations where $g\left(b^{*}\right)=0$ (not viable; up to $C \approx 10^{5}$ prey $/ \mathrm{m}^{3}$ ).

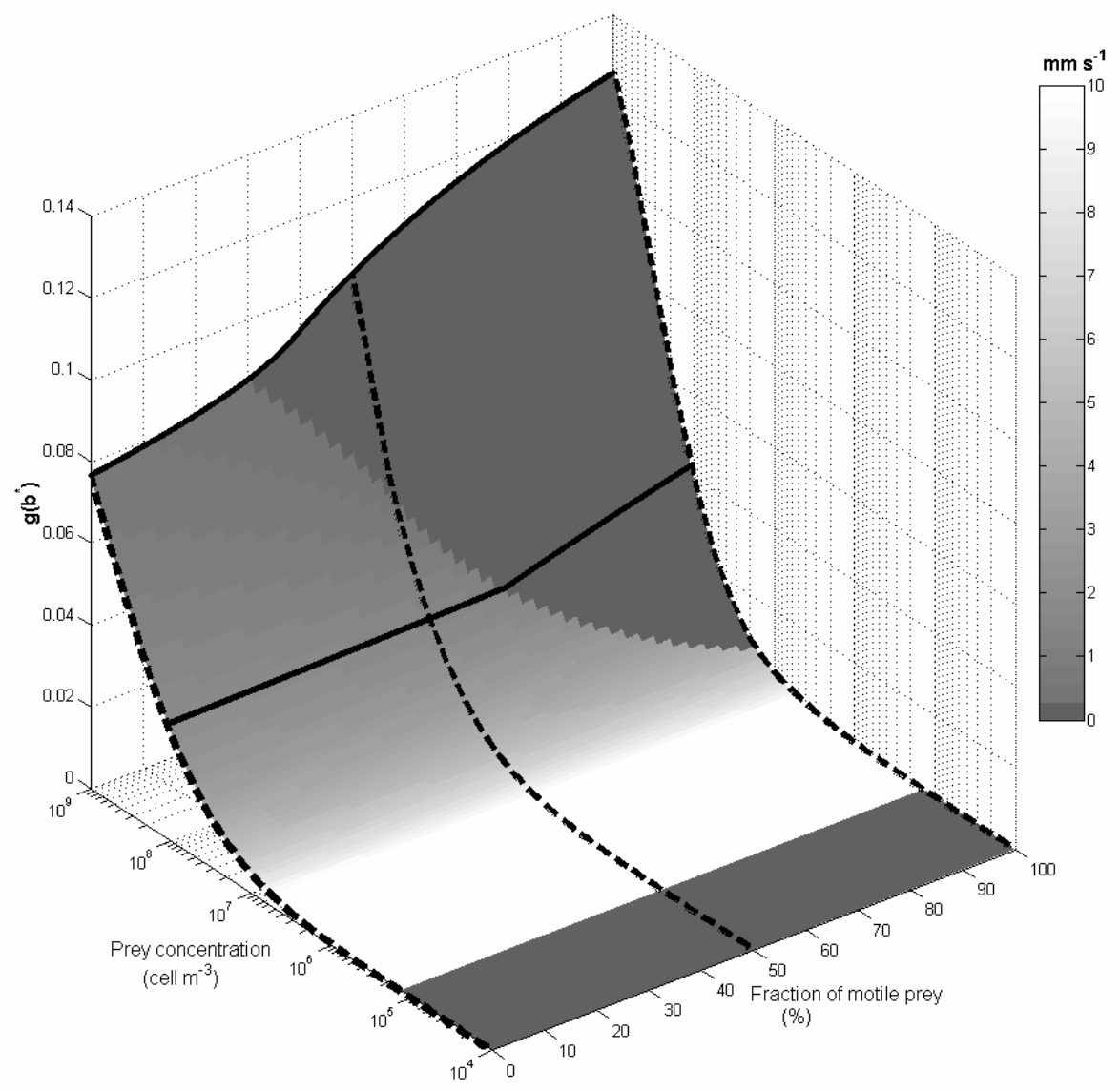


Figure 2 : Realized ingestion $(a, b)$ and mortality $(c, d)$ rates in Acartia tonsa when feeding on mixed prey composition ( 0 only static prey; 100 only motile prey) at two different concentrations $C=10^{8}$ prey $/ \mathrm{m}^{3}$ (a,c - solid lines) and $C=10^{9} \mathrm{prey} / \mathrm{m}^{3}$ (b,d - dashed lines). The predator concentration is $\mathrm{P}=$ 40 predator $/ \mathrm{m}^{3}$.
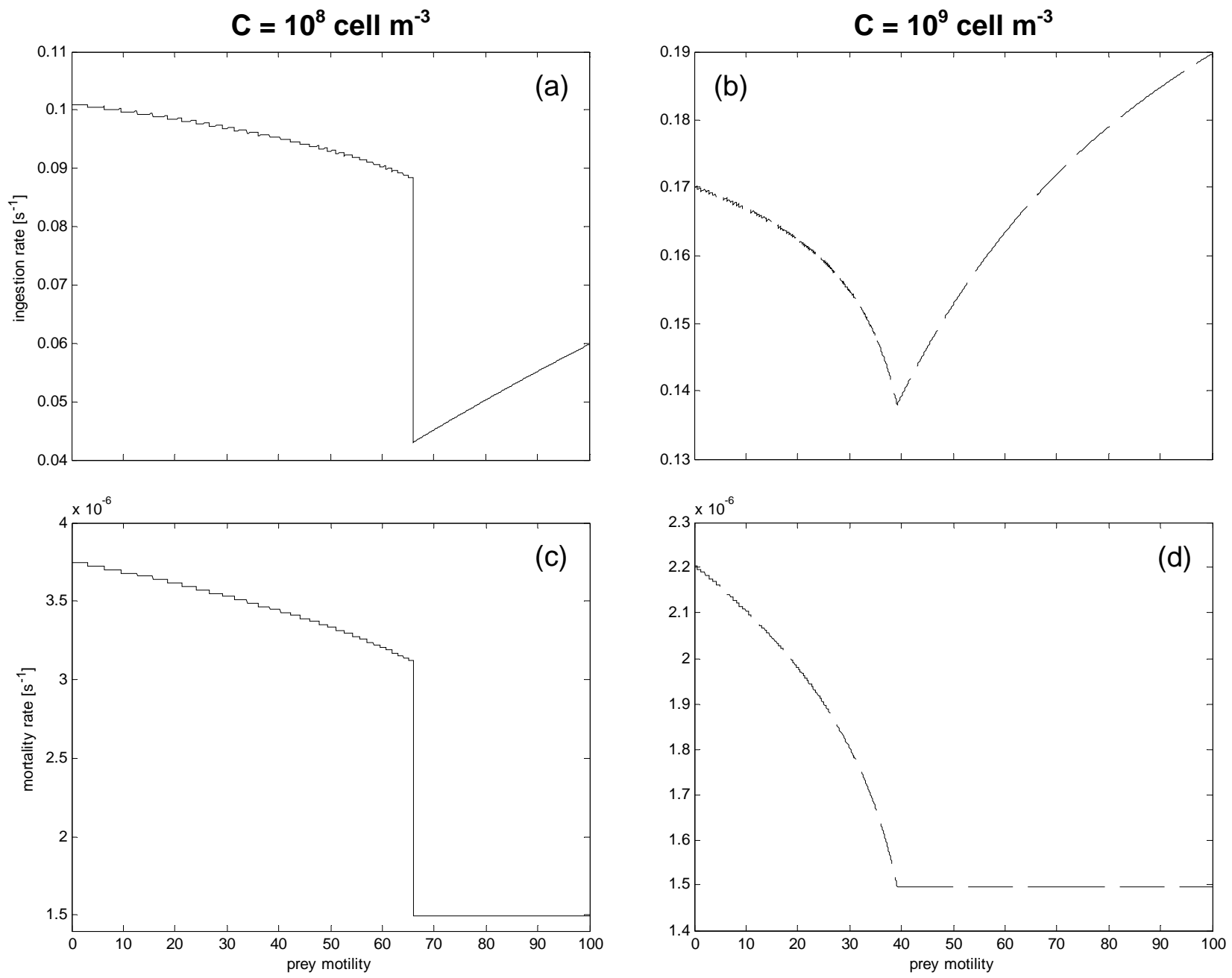

Figure 2 